\title{
Correlates of Physical Fighting among University Students in 25 Low and Middle Income and Emerging Economy Countries
}

\author{
Karl Peltzer \\ ASEAN Institute for Health Development, Madidol University, Salaya, Phutthamonthon, Nakhonpathom, Thailand, 73170, \\ University of Limpopo, Turfloop Campus, Sovenga 0727, South Africa, HIVIAIDS/STIs/and TB (HAST), \\ Human Sciences Research Council, Private Bag X41, Pretoria 0001, South Africa \\ Supa Pengpid \\ ASEAN Institute for Health Development, Madidol University, Salaya, Phutthamonthon, Nakhonpathom, \\ Thailand, 73170, University of Limpopo, Turfloop Campus, Sovenga 0727, South Africa \\ Email: supaprom@yahoo.com
}

Doi:10.5901/mjss.2014.v5n27p916

\begin{abstract}
The aim of this study was to estimate the prevalence and correlates of physical fighting among university students from 25 low and middle income and emerging economy countries. Using anonymous questionnaires, data were collected from 18541 university students, $41.9 \%$ men and $58.1 \%$ women, with a mean age of 20.8 years $(S D=2.9)$, from 25 countries across Africa, Asia and Americas. Overall, $13.1 \%$ reported to have been in one or more physical fights in the past 12 months, 20.0\% among men and $8.1 \%$ among women, ranging from below 5\% in China, Singapore and Nigeria to above 25\% in Pakistan and Russia. Multivariate logistic regression found that being male, higher economic status, weapon carrying, injury, tobacco use, binge drinking, illicit drug use, gambling, not always wearing a seatbelt, multiple sexual partners, depression, PTSD symptoms, childhood physical abuse and lack of social support were associated with physical fighting. Several clustering risk factors were identified which can be utilized in public health interventions.
\end{abstract}

Keywords: Physical fighting; Correlates; University students; Multi-country

\section{Introduction}

Youth violence has been identified as a global problem and physical fighting is probably the most common form of such violence (Krug, Mercy, Dahlberg, Zwi \& Lozano, 2002; Patton et al., 2009). Few studies have investigated physical fighting among university students. Among Turkish university students, it was found that $7.0 \%$ had engaged in physical fighting in the past year (Oksuz \& Malhan, 2005), among US college students, $32.7 \%$ of males and $17.3 \%$ of females had at least one physical fight in the previous six months (Marcus, Reio, Kessler, Cutler \& Fleury, 2000), and among adolescents and college students in China 19.3\% had engaged in physical fighting in the past 12 months (Zhou, Chen \& Dong, 2013). Compared to university students, an often higher prevalence of any physical fighting in the past 12 months was found among school-going adolescents in a number of countries, e.g., China 16.6\%, Egypt 54.8\%, Namibia 50.3\%, Indonesia 33.8\%, Philippines 50.0\% and Thailand 33\% (Swahn, Gressard, Palmier, Yao \& Haberlen, 2013), 2 or 3 times physical fighting in Grenada 25.2\% and Jamaica 30\% (Peltzer \& Pengpid, 2014).

Previous research found that male gender (Marcus et al., 2000; Oksuz \& Malhan, 2005; Pickett et al., 2013) and low economic status (Bailey, 2011; Pickett et al., 2013; Shetgiri, Kataoka, Ponce, Flores \& Chung, 2010) has been found to be associated with physical fighting among young people. Research also indicates a relationship between risk-taking behaviours such as substance use (alcohol use, smoking, drug use) (Fraga, Ramos, Dias \& Barros, 2011; Rudatsikira et al., 2008; Shetgiri et al., 2010), gambling (Slavin et al., 2013), carrying a weapon to school (Muula, Rudatsikira \& Siziya, 2008), injury (Pickett 2005) and not using seatbelts (Alikasifoglu et al., 2004) and physical fighting among youth. Agnew (1992) proposes that different sources of strain, including the presence of negative stimuli, e.g., childhood abuse (Alikasifoglu et al., 2004), may increase negative emotions such as anxiety (Smith-Khuri et al., 2004), dissatisfaction (MacDonald, Piquero, Valois \& Zullig, 2005) and depression (Celedonia, Wilson, El Gammal \& Hagras, 2013; Shetgiri et al., 2010), which in turn increase the probability of violent behaviour to occur (MacDonald et al., 2005). On the other hand, individuals who have prosocial mechanisms to cope with negative emotions and feelings may not turn into violent 
behaviour (Agnew, 1992). In line with this finding, various studies (Celedonia et al., 2013; Shetgiri et al., 2010; Springer, Parcel, Baumler \& Ross, 2006) found that lack of social support was associated with physical fighting.

The aim of this study was to estimate the prevalence and correlates of physical fighting among university students from 25 low and middle income and emerging economy countries.

\section{Methods}

\subsection{Participants and procedures}

This cross-sectional study was carried out with a network of collaborators in participating countries (see Acknowledgments). The anonymous, self-administered questionnaire used for data collection was developed in English, then translated and back-translated into languages (Arabic, Bahasa, French, Lao, Russian, Spanish, Thai, Turkish) of the participating countries. The study was initiated through personal academic contacts of the principal investigators. These collaborators arranged for data to be collected from intended 400 male and 400 female undergraduate university students aged 16-30 years by trained research assistants in 2013 in one or two universities in their respective countries. The universities involved were located in the capital cities or other major cities in the participating countries. Research assistants working in the participating universities asked classes of undergraduate students to complete the questionnaire at the end of a teaching class. Classes were recruited according to timetable scheduling using stratified random sampling. The students who completed the survey varied in the number of years for which they had attended the university. A variety of majors were involved, including education, humanities and arts, social sciences, business and law, science, engineering, manufacturing and construction, agriculture, health and welfare and services. Informed consent was obtained from participating students, and the study was conducted in 2013. Participation rates were in most countries over $90 \%$. Ethics approvals were obtained from institutional review boards from all participating institutions.

\subsection{Measures}

\subsubsection{Physical fight}

For the main outcome, study participants were asked, "During the past 12 months, how many times were you in a physical fight?" Response options ranged from "0 times", "1 time", "2 or 3 times", "4 or 5 times", "6 or 7 times", "8 or 9 times", "10 or 11 times" or "12 or more times". (CDC, 2013). For the purpose of our analyses, participants were classified as having participated in a physical fight if they reported being in one or more fights (CDC, 2013).

\subsection{Socio-demographic}

Socio-demographic questions included age, gender, and socioeconomic background were assessed by rating their family background as wealthy (within the highest $25 \%$ in "country", in terms of wealth), quite well off (within the $50 \%$ to $75 \%$ range for their country), not very well off (within the $25 \%$ to $50 \%$ range from "country"), or quite poor (within the lowest $25 \%$ in their country, in terms of wealth) (Wardle \& Steptoe, 1991). We subsequently divided the students into poorer (not very well off and quite poor) and wealthier (wealthy, quite well off) categories.

\subsection{Risk behaviour}

Weapon carrying was assessed with the question, "During the past 30 days, on how many days did you carry a weapon such as a gun, knife, or club? Do not count carrying a weapon as part of your job." Response options ranged from 1=0 days to $5=6$ or more days.

Injury. Participants were asked, "During the past 12 months, how many times were you seriously injured?" (serious injury was defined as "when it makes you miss at least one full day of usual activities (such as university, sports, or a job) or requires treatment by a doctor or nurse). Eight options were provided, ranging from $1=0$ times to $8=12$ or more times. A response of "0" was described as not having sustained a serious injury, while a response of one or more times was classified as having experienced a serious injury (CDC, 2013).

Tobacco use was assessed with the question: Do you currently use one or more of the following tobacco products (cigarettes, snuff, chewing tobacco, cigars, etc.)? Response options were "yes" or "no" (WHO, 1998).

Binge drinking was assessed with one item, "How often do you have (for men) five or more and (for women) four or 
more drinks on one occasion?" Response options ranged from 1=never to 5=daily or almost daily (Babor, Higgins-Biddle, Saunders \& Monteiro, 2001).

Illicit drug use was assessed with the question, "How often have you taken drugs in the past 12 months; other than prescribed by the health care provider."

The South Oaks Gambling Screen (SOGS), a standardized measure of pathological gambling and gambling behaviours in their lifetime (Lesieur \& Blume, 1987) was used to assess 9 different gambling behaviours, e.g. "Played cards for money." Response options ranged from 1=not at all to 3=Once a week or more. Cronbach alpha for this 9 item scale was 0.91 in this sample.

Seat belt use was assessed with the question, "When driving or riding in the front seat of a car do you wear a seat belt?" Response options were, All the time, Some of the time, Never, I don't ride in cars (Wardle \& Steptoe, 1991).

Sexual risk behaviour was assessed with the number of sexual partners they have had in the past 12 months.

\subsection{Negative emotions and stimuli}

Life satisfaction, "All things considered, how satisfied are you with your life as a whole?"(Rated from 1=very satisfied to 5=very dissatisfied (Wardle \& Steptoe, 1991).

Centers for Epidemiologic Studies Depression Scale (CES-D). We assessed depressive symptoms using the 10item version of the CES-D (Andresen et al., 1994). Scoring is classified from 0-9 as having a mild level of depressive symptoms, 10 to 14 as moderate depressive symptoms, and $\geq 15$ representing severe depressive symptoms (Kilbourne et al., 2002). The Cronbach a reliability coefficient of this 10 -item scale was 0.78 in this study.

Post traumatic stress disorder (PTSD). Breslau's 7-item screener was used to identify PTSD symptoms in the past month (Kimerling et al., 2006). Items asked whether the respondent had experienced difficulties related to a traumatic experience (e.g., "Did you begin to feel more isolated and distant from other people?"). The Cronbach alpha reliability coefficient of this 7 -item scale was 0.75 in this study.

History of child physical and sexual abuse was assessed with two questions.

\subsection{Protective factors}

Social support. Three items were drawn from the Social Support Questionnaire to assess perceived social support (Brock, Sarason, Sarason \& Pierce, 1996). The items were selected to reflect perceived tangible and emotional support, e.g.,"If I were sick and needed someone to take me to a doctor I would have trouble finding someone." These items were responded to on 4-point scales, $1=$ completely true, to $4=$ completely false, and summed to a score with a range of 3-12. Cronbach's alpha for this sample was 0.85 .

\section{Data Analysis}

Data analysis was performed using STATA software version 11.0 (Stata Corporation, College Station, Texas, USA). Descriptive statistics were used for reporting the proportion of physical fighting and Pearson Chi-square for gender differences in proportion of physical fighting. Logistic regression was used to assess the association between sociodemographic variables, risk behaviour, negative emotion and stimuli, protective factors and physical fighting. Variance inflation factor (VIF) and tolerance values for each model indicate multicollinearity was not a concern in any of the multivariate analyses. Since the study used a clustered design, country was included as a clustering variable in the regression models.

\section{Results}

\subsection{Sample characteristics}

The sample included 18541 university students, $41.9 \%$ men and $58.1 \%$ women, with a mean age of 20.8 years (SD=2.9), from 25 countries across Africa, Asia and Americas. Overall, 13.1\% reported to have been in one or more physical fights in the past 12 months; $20.0 \%$ among men and $8.1 \%$ among women. The overall prevalence of physical fighting among university students differed by country, ranging from below $5 \%$ in China, Singapore and Nigeria to above $25 \%$ in Pakistan and Russia. Although the preponderance of physical fighting among men was true for students from 21 study countries, there were no significant gender differences in the prevalence of physical fighting in 4 countries (see Table 1 ). 
Table 1: Physical fighting prevalence in the past 12 months among university students by country and gender ( $N=18541)$

\begin{tabular}{|c|c|c|c|c|c|}
\hline Country & $\mathrm{N}$ & $\%(95 \% \mathrm{Cl})$ & Male & Female & $x^{2}$ \\
\hline All & 18541 & $13.1(12.6-13.6)$ & 20.0 & 8.1 & $P<0.001$ \\
\hline \multicolumn{6}{|c|}{ Caribbean and South America } \\
\hline Barbados $^{4}$ & 561 & $8.7(6.4-11.1)$ & 10.6 & 6.3 & 0.078 \\
\hline Grenada $^{3}$ & 418 & $9.3(6.5-12.1)$ & 19.9 & 4.3 & $<0.001$ \\
\hline Jamaica $^{3}$ & 747 & $8.8(6.8-10.9)$ & 11.4 & 8.1 & 0.181 \\
\hline Colombia $^{3}$ & 816 & $16.4(13.9-19.0)$ & 23.9 & 10.5 & $<0.001$ \\
\hline Venezuela $^{3}$ & 564 & $7.3(5.1-9.4)$ & 11.1 & 4.7 & 0.005 \\
\hline \multicolumn{6}{|c|}{ Sub-Saharan Africa } \\
\hline Cameroon $^{2}$ & 627 & $22.5(19.2-28.8)$ & 38.4 & 10.6 & $<0.001$ \\
\hline Ivory Coast ${ }^{2}$ & 764 & $19.5(16.7-22.3)$ & 26.2 & 12.7 & $<0.001$ \\
\hline Madagascar $^{1}$ & 772 & $22.3(19.3-25.2)$ & 29.0 & 15.4 & $<0.001$ \\
\hline Mauritius $^{3}$ & 485 & $11.3(8.5-14.2)$ & 19.1 & 7.8 & $<0.001$ \\
\hline Namibia $^{3}$ & 472 & $8.7(6.1-11.2)$ & 19.8 & 5.3 & $<0.001$ \\
\hline Nigeria² $^{2}$ & 747 & $4.1(2.7-5.6)$ & 6.1 & 1.8 & 0.004 \\
\hline South Africa ${ }^{3}$ & 785 & $15.3(12.8-17.8)$ & 22.1 & 9.9 & $<0.001$ \\
\hline \multicolumn{6}{|c|}{ North Africa, Neareast and Central Asia } \\
\hline Egypt ${ }^{2}$ & 798 & $16.7(14.1-19.3)$ & 24.6 & 10.0 & $<0.001$ \\
\hline Turkey $^{3}$ & 799 & $6.8(5.0-8.5)$ & 10.5 & 3.0 & $<0.001$ \\
\hline Russia $^{3}$ & 794 & $27.3(24.2-30.4)$ & 44.5 & 10.9 & $<0.001$ \\
\hline Kyrgyzstan 1 & 837 & $22.8(19.9-25.7)$ & 44.3 & 7.5 & $<0.001$ \\
\hline \multicolumn{6}{|c|}{ South Asia and China } \\
\hline Bangladesh ${ }^{1}$ & 783 & $21.9(19.1-24.9)$ & 25.7 & 16.4 & 0.002 \\
\hline India ${ }^{2}$ & 800 & $7.9(6.0-9.7)$ & 9.2 & 5.0 & 0.038 \\
\hline Pakistan $^{2}$ & 813 & $26.6(23.5-29.6)$ & 34.4 & 20.9 & $<0.001$ \\
\hline China $^{3}$ & 1090 & $4.1(2.9-5.3)$ & 8.2 & 2.8 & $<0.001$ \\
\hline \multicolumn{6}{|l|}{ Southeast Asia } \\
\hline Indonesia ${ }^{2}$ & 750 & $8.4(6.4-10.4)$ & 15.6 & 5.2 & $<0.001$ \\
\hline Laos $^{2}$ & 806 & $5.5(3.9-7.0)$ & 3.7 & 6.4 & 0.108 \\
\hline Philippines $^{2}$ & 782 & $9.2(7.2-11.2)$ & 8.5 & 9.5 & 0.670 \\
\hline Singapore $^{4}$ & 883 & $4.3(3.0-5.6)$ & 5.8 & 2.8 & 0.025 \\
\hline Thailand $^{3}$ & 848 & $9.3(7.4-11.2)$ & 17.9 & 6.1 & $<0.001$ \\
\hline
\end{tabular}

1Low income country; ' Lower middle income country; ${ }^{3}$ Upper middle income country; ${ }^{4}$ High income country (Source: World Bank, 2013).

\subsection{Associations with physical fighting}

In multivariate logistic regression, it was found that sociodemographic factors (being male, coming from a wealthier family background and living in a higher income country), risk behaviours (weapon carrying in the past month, having sustained an injury in the past 12 months, current tobacco user, binge drinking, illicit drug use, frequent gambling, not always wearing a seat belt, multiple sexual partners in the past year), negative emotions and stimuli (depression, PTSD symptoms and childhood physical abuse) and lack of social support were associated with physical fighting (see Table 2). 
Table 2: Logistic regression analysis for association between independent variables and physical fighting

\begin{tabular}{|c|c|c|}
\hline Variables (\%) & Crude Odds ratio $(95 \% \mathrm{Cl})$ & Adjusted Odds ratio $(95 \% \mathrm{Cl})$ \\
\hline \multicolumn{3}{|l|}{ Sociodemographics } \\
\hline \begin{tabular}{|l|} 
Age in years \\
$16-19(34.8 \%)$ \\
$20-21(34.9 \%)$ \\
$22-30(30.3 \%)$ \\
\end{tabular} & $\begin{array}{c}1.00 \\
1.03(0.93-1.14) \\
1.00(0.90-1.12) \\
\end{array}$ & -- \\
\hline $\begin{array}{l}\text { Gender } \\
\text { Female }(58.1 \%) \\
\text { Male }(41.9 \%) \\
\end{array}$ & $\begin{array}{c}1.00 \\
2.85(2.61-3.11)^{\star * *}\end{array}$ & $\begin{array}{c}1.00 \\
1.82(1.59-2.09)^{\star \star \star}\end{array}$ \\
\hline \begin{tabular}{|l} 
Family economic background \\
Quite poor/not very well off (46.5\%) \\
Wealthy/quite well-off (53.5\%) \\
\end{tabular} & $\begin{array}{c}1.00 \\
1.33(1.22-1.46)^{\star \star \star}\end{array}$ & $\begin{array}{c}1.00 \\
1.54(1.35-1.77)^{\star \star \star}\end{array}$ \\
\hline $\begin{array}{l}\text { Country income } \\
\text { Low income/Lower middle income (50.2\%) } \\
\text { Upper middle income/High income (49.8\%) }\end{array}$ & $\begin{array}{c}1.00 \\
1.56(1.44-1.71)^{\star \star \star}\end{array}$ & $\begin{array}{c}1.00 \\
2.18(1.89-2.51)^{\star \star \star}\end{array}$ \\
\hline \multicolumn{3}{|l|}{ Risk behaviour } \\
\hline Weapon carrying (5.9\%) & $9.49(8.31-10.82)^{\star \star \star}$ & $5.99(4.92-7.29)^{\star \star \star}$ \\
\hline Injury $(25.2 \%)$ & $2.23(2.04-2.44)^{\star \star \star}$ & $1.94(1.69-2.21)^{\star \star \star}$ \\
\hline Current tobacco use (12.3\%) & $3.57(3.21-3.97)^{\star \star \star}$ & $1.83(1.57-2.13)^{\star \star \star}$ \\
\hline Binge drinking (at least once/month) (12.1\%) & $2.10(1.88-2.34)^{\star \star \star}$ & $1.33(1.11-1.58)^{\star \star}$ \\
\hline Illicit drug use (past year) (19.9\%) & $1.78(1.61-1.96)^{\star \star \star}$ & $1.39(1.20-1.60)^{\star \star \star}$ \\
\hline Gambling (>once past week) (8.2\%) & $2.61(2.31-2.95)^{\star \star \star}$ & $1.50(1.23-1.83)^{\star \star \star}$ \\
\hline Not always using seatbelt (53.1\%) & $1.53(1.39-1.68)^{\star \star \star}$ & $1.39(1.22-1.59)^{\star \star \star}$ \\
\hline Sexual risk behaviour (two or more sexual partners in past year) (19.2\%) & $3.08(2.79-3.40)^{\star \star \star}$ & $2.15(1.86-2.49)^{\star \star \star}$ \\
\hline \multicolumn{3}{|l|}{\begin{tabular}{|l|} 
Negative emotions and stimuli \\
\end{tabular}} \\
\hline Life satisfaction (very dissatisfied) (15.4\%) & $1.21(1.08-1.36)^{\star \star \star}$ & $1.14(0.97-1.35)$ \\
\hline Depression (moderate to severe) (36.5\%) & $1.51(1.38-1.64)^{\star \star \star}$ & $1.18(1.03-1.34)^{\star}$ \\
\hline PTSD (20.5\%) & $1.76(1.60-1.95)^{\star \star \star}$ & $1.40(1.21-1.64)^{\star \star \star}$ \\
\hline Childhood physical abuse (5.0\%) & $2.09(1.77-2.97)^{\star \star \star}$ & $1.31(1.00-1.74)^{\star}$ \\
\hline Childhood sexual abuse (2.7\%) & $1.39(1.08-1.79)^{\star \star}$ & $0.86(0.55-1.33)$ \\
\hline \multicolumn{3}{|l|}{ Protective factors } \\
\hline $\begin{array}{l}\text { Social support } \\
\text { Low }(17.9 \%) \\
\text { Medium }(37.5 \%) \\
\text { High }(44.7 \%) \\
\end{array}$ & $\begin{array}{c}1.00 \\
0.62(0.56-0.69)^{\star \star \star} \\
0.55(0.50-0.62)^{\star \star \star}\end{array}$ & $\begin{array}{c}1.00 \\
0.85(0.72-1.01) \\
0.84(0.71-0.99)^{*}\end{array}$ \\
\hline
\end{tabular}

${ }^{* \star *} \mathrm{P}<.000,{ }^{* *} \mathrm{P}<.01,{ }^{*} \mathrm{P}<.05$

\section{Discussion}

The study found, among a large sample of university students from 25 low, middle income and emerging economy countries across Asia, Africa and the Americas, a significant proportion (13.1\%) reporting to have been in one or more physical fights in the past 12 months, which is comparable to previous studies in middle income countries such as Turkey (Oksuz \& Malhan, 2005) and China (Zhou et al., 2013), but seems to be lower than in a College student sample in the USA (Marcus et al., 2000). However, the study found a large country variation in the overall prevalence, physical fighting among university students, ranging from below $5 \%$ in China, Singapore and Nigeria to above $25 \%$ in Pakistan and Russia. As for the high prevalence of physical fighting among Russian students, a previous study (Lysova \& Douglas, 2008) also found a high occurrence of different types of intimate partner violence among male and female Russian university students. Likewise, in a review a high prevalence of intimate partner violence was found in Pakistan (Ali, Naylor, Croot \& O'Cathain, 2014). Using the same measure for physical fighting, other studies with school-going adolescents (Peltzer \& Pengpid, 2014; Swahn et al., 2013), seem to have generally found a lower prevalence of physical fighting in a number of our study countries, including China, Egypt, Namibia, Indonesia, Philippines and Thailand.

In most study countries men were more likely to be engaged in physical fights than women, which concurs with previous studies (Marcus et al., 2000; Oksuz \& Malhan, 2005; Pickett et al., 2013). However, in four study countries (Barbados, Jamaica, Laos and the Philippines) there were no significant gender differences in the prevalence of physical fighting. This may be attributed to the women's position in society (Rahav, Wilsnack, Bloomfield, Gmel \& Kuntsche, 
2006). It is possible that in these study countries, a higher women's position in the society reduces the difference between men and women physical fighting rates. In this study, students who had a wealthier economic family background and those who were residing in the upper middle income and high income countries were more likely to engage in physical fighting than students with a poorer family background and those living in low income and lower middle income countries. This finding is contrary to what was found in a few studies with school-going adolescents (Bailey, 2011; Pickett et al., 2013; Shetgiri et al., 2010), where lower economic status was associated with a higher prevalence of physical fighting. It is possible that higher levels of economic status may result in social conditions that promote the acceptance of violence within developing country societies.

In agreement with previous studies (Alikasifoglu et al., 2004; Fraga et al., 2011; Muula et al., 2008; Pickett, 2005; Rudatsikira et al., 2008; Shetgiri et al., 2010; Slavin et al., 2013), this study found a co-occurrence between physical fighting and a wide range of risk behaviours including weapon carrying, injury, tobacco use, binge drinking, illicit drug use, frequent gambling, not always wearing a seatbelt, and multiple sexual partners. This clustering of a number of risk behaviours may call for an intervention to include multiple risk behaviours.

Regarding the study of negative emotions and stimuli, this study found an agreement with some previous studies (Alikasifoglu et al., 2004; Celedonia et al., 2013; Shetgiri et al., 2010) that depression, PTSD symptoms and childhood physical abuse were associated with physical fighting. Life dissatisfaction was in a previous study (MacDonald, et al., 2005) associated with physical fighting, while in this study it was significant at the bivariate level. It is possible that due to the one-item measure of life satisfaction, the association with physical fighting became non-significant at multivariate level. Further, lack of social support was associated with physical fighting, which is in line with previous studies (Celedonia et al., 2013; Shetgiri et al., 2010; Springer et al., 2006). This could possibly mean that the promotion of prosocial mechanisms could reduce violent behaviour (Agnew, 1992).

\section{Limitations of the Study}

This study had several limitations. The study was cross-sectional, so causal conclusions cannot be drawn. The investigation was carried out with students from one or two universities in each country, and inclusion of other centres could have resulted in different results. University students are not representative of young adults in general, and the physical fighting levels, sociodemographic, risk behaviours and health variables may be different in other sectors of the population. A further limitation of the study was that all information collected in the study was based on self-reporting. It is possible that certain behaviours were under or over reported. Underreporting of self-reported physical fighting may be attributed to social stigma, for women in particular, thus possibly influencing the validity of this self-reported data. However, in this study the questionnaire was self-administered rather than interview-administered which may have helped to mitigate under-reporting of physical fighting. Another limitation may be that physical fighting was assessed with a single item in this study, and contextual factors, type of violence, victimization or perpetration were not assessed (Bossarte, Simon \& Swahn, 2008; Brewer \& Swahn, 2005; Swahn, Simon, Aries \& Bossarte, 2008).

\section{Conclusion}

The study found, among a large sample of university students from 25 low, middle income and emerging economy countries across Asia, Africa and the Americas, a significant proportion of physical fighting. The clustering of other risk behaviours such as weapon carrying, injury, tobacco use, binge drinking, drug use, gambling, seatbelt use and sexual risk behaviour suggest that public health interventions aiming at the prevention of interpersonal violence in university students should factor in these other problem behaviours.

\section{Acknowledgements}

Partial funding for this study was provided by the South African Department of Higher Education. The following colleagues participated in this student health survey and contributed to data collection (locations of universities in parentheses) Bangladesh: Gias Uddin Ahsan (Dhaka); Barbados: T. Alafia Samuels (Bridgetown); Cameroon: Jacques Philippe Tsala Tsala (Yaounde); China: Tony Yung and Xiaoyan Xu (Hong Kong and Chengdu); Colombia: Carolina Mantilla (Pamplona); Egypt: Alaa Abou-Zeid (Cairo); Grenada: Omowale Amuleru-Marshall (St. George); India: Krishna Mohan (Visakhapatnam); Indonesia: Indri Hapsari Susilowati (Jakarta); Ivory Coast: Issaka Tiembre (Abidjan); Jamaica: Caryl James (Kingston); Kyrgyzstan: Erkin M Mirrakhimov (Bishkek); Laos: Vanphanom Sychareun (Vientiane); Madagascar: Onya H Rahamefy (Antananarivo); Mauritius: Hemant Kumar Kassean (Réduit, Moka); Namibia: Pempelani 
Mufune (Windhoek); Nigeria: Solu Olowu (lle-Ife); Pakistan: Rehana Reman (Karachi); Philippines: Alice Ferrer (Miagao); Russia: Alexander Gasparishvili (Moscow); Singapore: Mee Lian Wong (Singapore); South Africa: Tholene Sodi (Polokwane); Thailand: Tawatchai Apidechkul (Chiang Rai); Turkey: Neslihan Keser Özcan (Istanbul); Venezuela: Yajaira M Bastardo (Caracas).

\section{References}

Agnew, R. (1992). Foundations for a general strain theory of crime and delinquency. Criminology, 30, 47-87.

Ali, P. A., Naylor, P. B., Croot, E., \& O'Cathain, A. (2014). Intimate partner violence in Pakistan: A systematic review. Trauma Violence Abuse, Mar 12,_doi: 10.1177/1524838014526065.

Alikasifoglu, M., Erginoz, E., Ercan, O., Uysal, O., Kaymak, D.A., \& liter, O. (2004). Violent behaviour among Turkish high school students and correlates of physical fighting. European Journal of Public Health, 14(2), 173-7.

Andresen, E. M., Malmgren, J. A., Carter, W. B., Patrick, D. L. (1994). Screening for depression in well older adults: evaluation of a short form of the CES-D (Center for Epidemiologic Studies Depression Scale). American Journal of Preventive Medicine, 10(2), 77-84.

Babor, T. F., Higgins-Biddle, J. C., Saunders, J. B., Monteiro, M. (2001). AUDIT: The Alcohol Use Disorder Identification Test. Geneva, Switzerland: World Health Organization.

Bailey, A. (2011). The Jamaican adolescent's perspective on violence and its effects. West Indian Medical Journal, 60(2), 165-71.

Bossarte, R. M., Simon, T. R., \& Swahn, M. H. (2008). Clustering of adolescent dating violence, peer violence, and suicidal behavior. Journal of Interpersonal Violence, 23(6), 815-33.

Brewer, R. D., \& Swahn, M. H. (2005). Binge drinking and violence. Journal of the Medical Association of America, 294(5), 616-8.

Brock, D., Sarason, I., Sarason, B., \& Pierce, G. (1996). Simultaneous assessment of perceived global and relationship-specific support. Journal of Social and Personal Relationships, 13, 143-152.

Celedonia, K. L., Wilson, M. L., El Gammal, H. A., \& Hagras, A. M. (2013). Physical fighting among Egyptian adolescents: social and demographic correlates among a nationally representative sample. Peer Journal, 1, e125.

Fraga, S., Ramos, E., Dias, S., \& Barros, H. (2011). Physical fighting among school-going Portuguese adolescents: social and behavioural correlates. Preventive Medicine, 52(5), 401-4.

Krug, E. G., Mercy, J., Dahlberg, L., Zwi, A., \& Lozano, R. (2002). World report on violence and health. Geneva, Switzerland: World Health Organization.

Kilbourne, A., Justice, A., Rollman, B., McGinnis, K., Rabeneck, L., Weissman, S., ... Rodriguez-Barradas, M. (2002). Clinical importance of HIV and depressive symptoms among veterans with HIV infection. Journal of General and Internal Medicine, 17(7), $512-520$.

Kimerling, R., Ouimette, P., Prins, A., Nisco, P., Lawler, C., Cronkite, R., \& Moos, R. H. (2006). Brief report: Utility of a short screening scale for DSM-IV PTSD in primary care. Journal of General and Internal Medicine, 21, 65-67.

Lesieur, H. R., \& Blume, S. B. (1987). The South Oaks Gambling Screen (SOGS): A new instrument for the identification of pathological gamblers. American Journal of Psychiatry, 144, 1184-1188.

Lysova, A.V., \& Douglas, E. M. (2008). Intimate partner violence among male and female Russian university students. Journal of Interpersonal Violence, 23(11), 1579-99.

MacDonald, J. M., Piquero, A. R., Valois, R. F., \& Zullig, K. J. (2005). The relationship between life satisfaction, risk-taking behaviors, and youth violence. Journal of Interpersonal Violence, 20, 1495 DOI: 10.1177/0886260505278718.

Marcus, R., Reio, T., Kessler, L., Cutler, K., \& Fleury, J. (2000). Interpersonal violence between College Students: Proximal influences. Paper presented at the Annual Convention of the American Psychological Association (108th, Washington, DC,August 4-8, 2001).

Muula, A. S., Rudatsikira, E., \& Siziya, S. (2008). Correlates of weapon carrying among high school students in the United States. Annals of General Psychiatry,7, 8. doi: 10.1186/1744-859X-7-8.

Oksuz, E., \& Malhan, S. (2005). Socioeconomic factors and health risk behaviors among university students in Turkey: questionnaire study. Croatian Medical Journal, 46(1), 66-73.

Patton, G. C., Coffey, C., Sawyer, S. M., Viner, R. M., Haller, D. M., Bose, K., ... Mathers, C.D. (2009). Global patterns of mortality in young people: a systematic analysis of population health data. Lancet, 374(9693), 881-92.

Peltzer, K., \& Pengpid, S. (2014). Physical fighting and social correlates among in-school adolescents in the Caribbean. Mediterranean Journal of Social Sciences, 5(14), 531-538.

Pickett, W., Craig, W., Harel, Y., Cunningham, J., Simpson, K., \& Molcho, M., ... HBSC Violence and Injuries Writing Group (2005). Cross-national study of fighting and weapon carrying as determinants of adolescent injury. Pediatrics, 116(6), e855-63.

Pickett, W., Molcho, M., Elgar, F. J., Brooks, F., de Looze, M., Rathmann, K., ... Currie, C. (2013). Trends and socioeconomic correlates of adolescent physical fighting in 30 countries. Pediatrics, 131(1), e18-26.

Rudatsikira, E., Mataya, R. H., Siziya, S., \& Muula, A. S. (2008). Association between bullying victimization and physical fighting among Filipino adolescents: results from the Global School-Based Health Survey. Indian Journal of Pediatrics, 75(12), 1243-7.

Shetgiri, R., Kataoka, S., Ponce, N., Flores, G., \& Chung, P. J. (2010). Adolescent fighting: racial/ethnic disparities and the importance of families and schools. Academic Pediatrics, 10(5), 323-9.

Slavin, M., Pilver, C. E., Hoff, R. A., Krishnan-Sarin, S., Steinberg, M. A., Rugle, L., \& Potenza, M. N. (2013). Serious Physical Fighting and Gambling-Related Attitudes and Behaviors in Adolescents. Journal of Behavioral Addictions, 2(3), 167. 
Smith-Khuri, E., Iachan, R., Scheidt, P. C., Overpeck, M. D., Gabhainn, S. N., Pickett, W., \& Harel, Y. (2004). A cross-national study of violence-related behaviors in adolescents. Archives of Pediatrics \& Adolescent Medicine, 158(6), 539-44.

Swahn, M. H., Gressard, L., Palmier, J. B., Yao, H., \& Haberlen, M. (2013). The prevalence of very frequent physical fighting among boys and girls in 27 countries and cities: regional and gender differences. Journal of Environmental and Public Health, 2013, 215126.

Wardle, J., \& Steptoe, A. (1991). The European Health and Behaviour Survey: rationale, methods and initial results from the United Kingdom. Social Science and Medicine, 33, 925-36.

Centers for Disease Control (CDC) (2013). The Global School and Health Survey background. Available from http://www.cdc.gov/ gshs/background/index.htm at 15 April 2013.

Rahav, G., Wilsnack, R., Bloomfield, K., Gmel, G., \& Kuntsche, S. (2006). The influence of societal level factors on men's and women's alcohol consumption and alcohol problems. Alcohol and Alcoholism, 41(1), i47-55.

Springer A, Parcel G, Baumler E, Ross M. Supportive social relationships and adolescent health risk behavior among secondary school students in El Salvador. Soc Sci Med. 2006 Apr;62(7):1628-40. Epub 2005 Sep 19.

Swahn MH, Simon TR, Arias I, Bossarte RM. Measuring sex differences in violence victimization and perpetration within date and samesex peer relationships. J Interpers Violence. 2008 Aug;23(8):1120-38.

World Health Organization (WHO). Guidelines for controlling and monitoring the tobacco epidemic. Geneva, Switzerland: WHO, 1998.

Zhou, L., Chen, D., \& Dong, G. (2013). Characteristics and related factors of nonfatal injuries among adolescents and college students in Shenzhen City of China. BioMedCentral Public Health, 13, 392. doi: 10.1186/1471-2458-13-392. 